\title{
OPEN Histological assessment, anti-quorum sensing, and anti-biofilm activities of Dioon spinulosum extract: in vitro and in vivo approach
}

\author{
Engy Elekhnawy ${ }^{1 凶}$, Walaa A. Negm ${ }^{2 凶}$, Mona El-Aasr ${ }^{2}$, Amal Abo Kamer ${ }^{1}$, \\ Mohammed Alqarni ${ }^{3}$, Gaber El-Saber Batiha ${ }^{4}$, Ahmad J. Obaidullah ${ }^{5,6}$ \& Heba M. Fawzy
}

Pseudomonas aeruginosa is an opportunistic bacterium causing several health problems and having many virulence factors like biofilm formation on different surfaces. There is a significant need to develop new antimicrobials due to the spreading resistance to the commonly used antibiotics, partly attributed to biofilm formation. Consequently, this study aimed to investigate the antibiofilm and anti-quorum sensing activities of Dioon spinulosum, Dyer Ex Eichler extract (DSE), against $P$ seudomonas aeruginosa clinical isolates. DSE exhibited a reduction in the biofilm formation by $P$. aeruginosa isolates both in vitro and in vivo rat models. It also resulted in a decrease in cell surface hydrophobicity and exopolysaccharide quantity of $P$. aeruginosa isolates. Both bright field and scanning electron microscopes provided evidence for the inhibiting ability of DSE on biofilm formation. Moreover, it reduced violacein production by Chromobacterium violaceum (ATCC 12,472). It decreased the relative expression of 4 quorum sensing genes (lasl, lasR, rhll, rhlR) and the biofilm gene ( $n d v \mathrm{~B}$ ) using qRT-PCR. Furthermore, DSE presented a cytotoxic activity with $\mathrm{IC}_{50}$ of $4.36 \pm 0.52 \mu \mathrm{g} / \mathrm{ml}$ against human skin fibroblast cell lines. For the first time, this study reports that DSE is a promising resource of anti-biofilm and anti-quorum sensing agents.

Pseudomonas aeruginosa is an emerging opportunistic pathogen causing many nosocomial infections like wounds, respiratory and urinary tract infections ${ }^{1}$. The prevalence of $P$. aeruginos $a$ in humans is primarily linked to its ability to form biofilms when attached to biotic and abiotic surfaces. Biofilm is a complex population of bacteria present in an extracellular matrix made of lipids, exopolysaccharides (EPS), nucleic acids, and proteins ${ }^{2}$. This matrix can hamper the spread of different antibiotics through the formed biofilm; thus, antibiotic resistance is highly spreading among the bacterial population embedded in biofilms ${ }^{3}$.

Most bacteria, especially P. aeruginosa, communicate through quorum sensing (QS), a signalling mechanism between cells ${ }^{4}$. This mechanism requires the development of molecular signals called autoinducers (AIs) which spread in the surrounding environment and interact with their corresponding regulators leading to increasing biofilm formation and development of antibiotic resistance ${ }^{5}$.

The rapid dissemination of antibiotic resistance worldwide has directed the scientific community toward alternative antibiotics like non-antibiotic quorum sensing and biofilm inhibitors. This approach focuses on hindering the communication between bacterial cells without exerting selective pressure on them, therefore reducing the chance for the appearance of multidrug-resistant strains ${ }^{5}$.

${ }^{1}$ Pharmaceutical Microbiology Department, Faculty of Pharmacy, Tanta University, Tanta 31111, Egypt. ${ }^{2}$ Pharmacognosy Department, Faculty of Pharmacy, Tanta University, Tanta 31111, Egypt. ${ }^{3}$ Department of Pharmaceutical Chemistry, College of Pharmacy, Taif University, P.O. Box 11099, Taif 21944, Saudi Arabia. ${ }^{4}$ Department of Pharmacology and Therapeutics, Faculty of Veterinary Medicine, Damanhour University, Damanhour 22511, Egypt. ${ }^{5}$ Drug Exploration and Development Chair (DEDC), Department of Pharmaceutical Chemistry, College of Pharmacy, King Saud University, Riyadh 11451, Saudi Arabia. ${ }^{6}$ Department of Pharmaceutical Chemistry, College of Pharmacy, King Saud University, P.O. Box 2457, Riyadh 11451, Saudi Arabia. ${ }^{7}$ Histology and Cell Biology Department, Faculty of Medicine, Ain Shams University, Cairo, Egypt. ${ }^{\circledR}$ email: engy.ali@pharm.tanta.edu.eg; walaa.negm@pharm.tanta.edu.eg 


\begin{tabular}{|l|l|l|l|}
\hline Isolate number & MIC value $(\boldsymbol{\mu g} / \mathbf{m l})$ & Isolate number & MIC value $(\boldsymbol{\mu g} / \mathbf{m l})$ \\
\hline P1 & 250 & P19 & 250 \\
\hline P2 & 500 & P20 & 250 \\
\hline P3 & 500 & P21 & 500 \\
\hline P4 & 500 & P22 & 500 \\
\hline P5 & 250 & P23 & 1000 \\
\hline P6 & 1000 & P24 & 1000 \\
\hline P7 & 250 & P25 & 500 \\
\hline P8 & 250 & P26 & 250 \\
\hline P9 & 1000 & P27 & 500 \\
\hline P10 & 1000 & P28 & 250 \\
\hline P11 & 500 & P29 & 250 \\
\hline P12 & 250 & P30 & 250 \\
\hline P13 & 250 & P31 & 500 \\
\hline P14 & 500 & P32 & 1000 \\
\hline P15 & 500 & P33 & 500 \\
\hline P16 & 500 & P34 & 1000 \\
\hline P17 & 250 & P35 & 1000 \\
\hline P18 & 1000 & & \\
\hline
\end{tabular}

Table 1. MIC values of DSE against $P$. aeruginosa isolates.

Cycad plants are rich in a wide variety of active constituents. Dioon spinulosum, Dyer Ex Eichler, is one of the giant Cycads all over the world. Recently, D. spinulosum exhibited potent cytotoxic activity against different cell lines. D. spinulosum also displayed a promising in vivo hepatoprotective activity. Moreover, it presented antimicrobial, antioxidant, and high protective activities against DNA damage ${ }^{6,7}$.

Not much-reported work has been done in Egypt on different plants that show anti-quorum sensing and anti-biofilm activities. However, many Egyptian plants have been investigated for their anti-cancer, anti-diabetic, antioxidant activities. Thus, we decided in this study to examine D. spinulosum plant growing in Egypt for its anti-quorum sensing and anti-biofilm activities against $P$. aeruginosa clinical isolates.

\section{Results}

Minimal inhibitory concentration (MIC). The antibacterial activity of DSE against $P$. aeruginosa isolates was determined using broth microdilution assay. The MIC values of DSE ranged from 250 to $1000 \mu \mathrm{g} / \mathrm{ml}$, as shown in Table 1.

Determination of cell surface hydrophobicity (CSH). The CSH was investigated in P. aeruginosa isolates by calculating the hydrophobicity index (HI). A significant reduction $(\mathrm{p}<0.05)$ in the values of HI was detected in $45.7 \%$ of the tested isolates after treatment with DSE (using concentrations ranging from 125 to 500 $\mu \mathrm{g} / \mathrm{ml}$, which equal to $0.5 \mathrm{MIC}$ values) as displayed in Fig. 1 .

EPS quantification. EPS are the main constituents of biofilms; thus, they were quantified before and after treatment with DSE (using concentrations ranging from 125 to $500 \mu \mathrm{g} / \mathrm{ml}$ ) by the phenol-sulfuric acid method. A significant reduction $(\mathrm{p}<0.05)$ in the EPS quantity was noticed in $51.4 \%$ of $P$. aeruginosa isolates, as shown in Fig. 2.

In vitro biofilm inhibition assay and counting of colony-forming units (CFU). The effect of DSE on biofilm formation was estimated using the crystal violet assay to study whether DSE effectively inhibited biofilm formation by $P$. aeruginosa clinical isolates. We found that DSE decreased the percentage of $P$. aeruginosa isolates, which were strongly and moderately forming biofilm, from 77.1 to $34.3 \%$ (as shown in Table 2). The $\mathrm{CFU} / \mathrm{ml}$ values were expressed as mean \pm standard deviation $(\mathrm{SD})$, as presented in Fig. 3. A significant decrease in the number of $\mathrm{CFU} / \mathrm{ml}$ was detected in $34.3 \%$ of the isolates after treatment with DSE.

MTT tetrazolium test. The MTT tetrazolium test was applied to check out the cellular viability of $P$. aeruginosa isolates in the formed biofilm before and after treatment with DSE. A non-significant change $(\mathrm{p}>0.05)$ in the cell viability was observed after treatment with DSE.

Biofilm examination using compound brightfield and scanning electron microscopes (SEM). In order to study the effect of DSE on the biofilm morphology, the formed biofilm by P. aeruginosa with (treated isolates) and without (untreated isolates) DSE was examined using a BFM and SEM. A remarkable reduction in the biofilms formed by $P$. aeruginosa was revealed in 15 isolates. A representative example of the visible inhibition of the formed biofilm is shown in Figs. 4 and 5. 


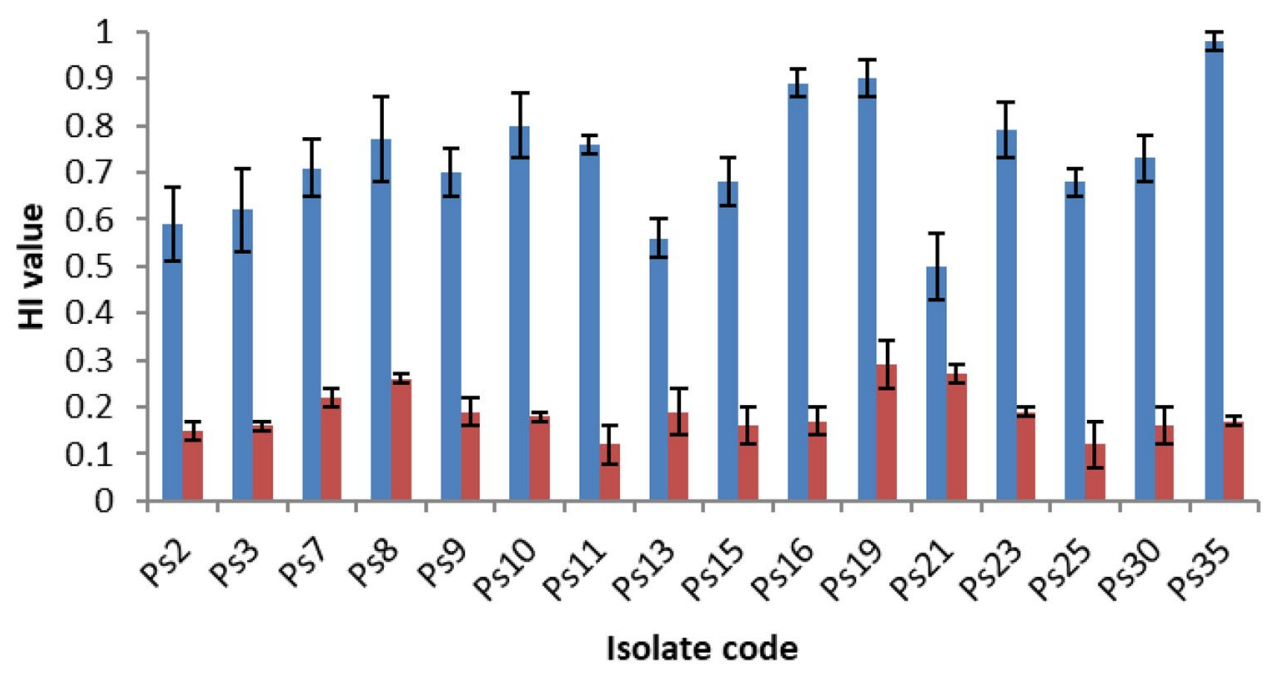

\section{Before treatment $\quad$ After treatment}

Figure 1. A diagram presenting the significant reduction $(\mathrm{p}<0.05)$ in the hydrophobicity index of $16 P$. aeruginosa isolates after treatment with DSE.

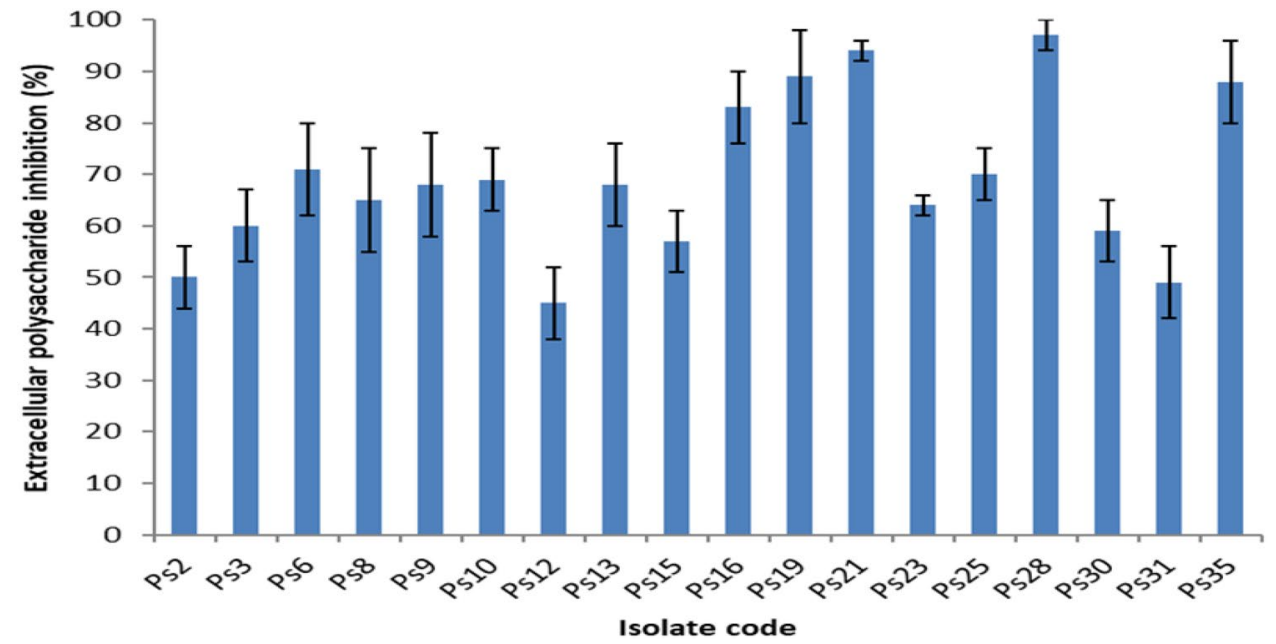

Figure 2. A chart showing the percentages of inhibition of the extracellular polysaccharide production in $18 P$. aeruginosa isolates after treatment with DSE.

\begin{tabular}{|l|l|l|}
\hline Biofilm formation ability & No. of isolates before treatment & No. of isolates after treatment \\
\hline NBP & 6 & 10 \\
\hline WBP & 2 & 13 \\
\hline MBP & 16 & 7 \\
\hline SBP & 11 & 5 \\
\hline
\end{tabular}

Table 2. Formation of biofilm by $P$. aeruginosa isolates before and after treatment with DSE (at concentrations ranged from 125 to $500 \mu \mathrm{g} / \mathrm{mL}$ ). $N B P$ non-biofilm producing isolate, $W B P$ weak biofilm-producing isolate, $M B P$ moderate biofilm-producing isolate, $S B P$ strong biofilm producing isolate.

Quantification of inhibition of violacein production. DSE exhibited an inhibitory effect on the pigment produced by the standard isolate Chromobacterium violaceum (ATCC 12472) in a concentration-dependent mode, as shown in Fig. 6. Maximum violacein inhibition of $44.9 \pm 0.9 \%$ was observed at a DSE concentration of $1000 \mu \mathrm{g} / \mathrm{ml}$. 


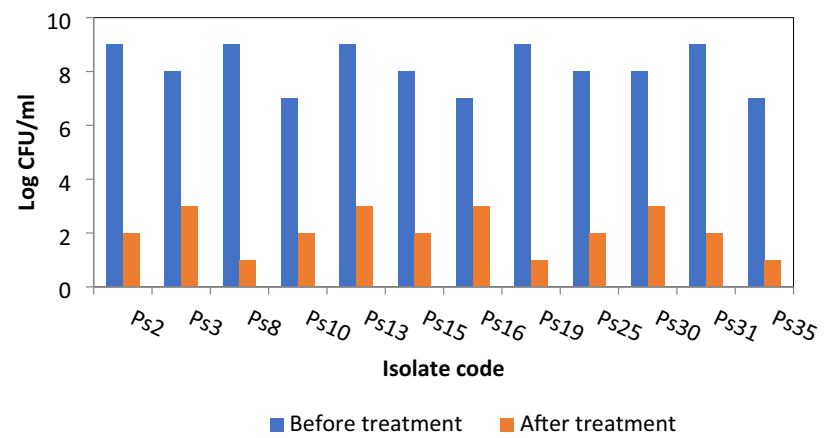

Figure 3. A chart showing significant reduction in the count of $\mathrm{CFU} / \mathrm{ml}$ of $P$. aeruginosa isolates after treatment with DSE using agar plating technique.
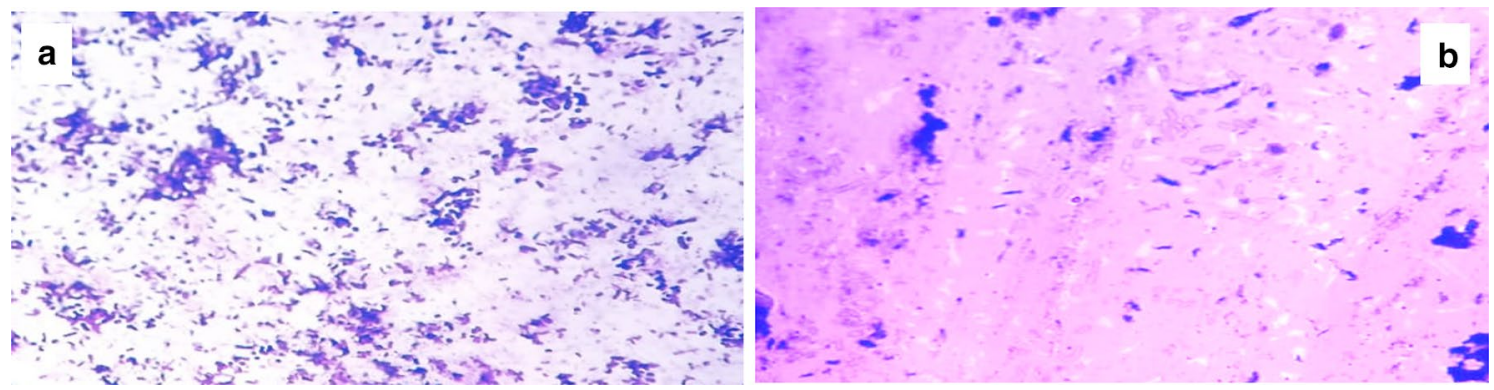

Figure 4. A representative example for the significant reduction in biofilm formation by $P$. aeruginosa isolates using bright field microscope: (a) before treatment, and (b) after treatment with DSE.
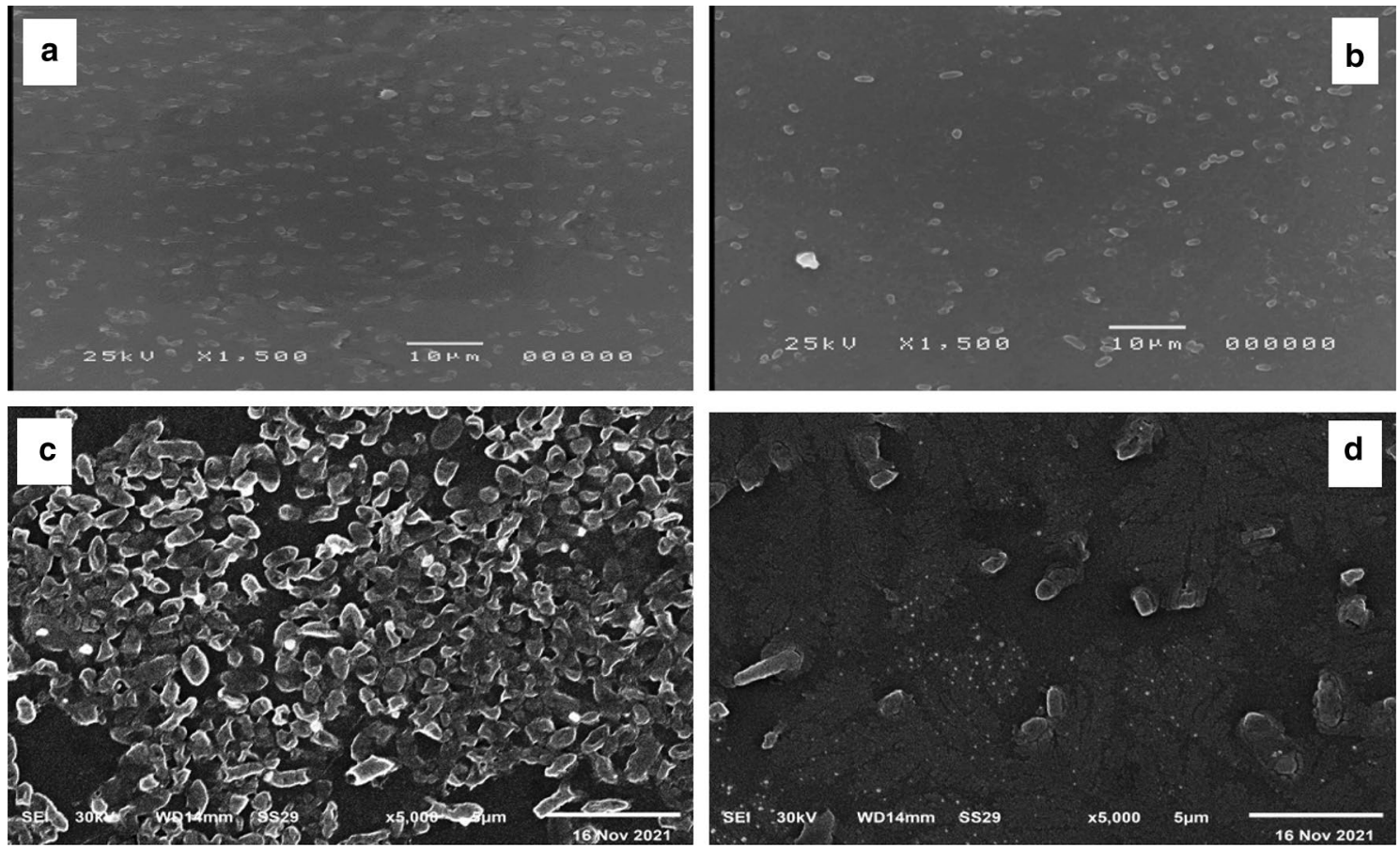

Figure 5. A representative example for the significant reduction in biofilm formation by $P$. aeruginosa isolates using SEM: (a,c) before treatment, (b,d) after treatment with DSE. 


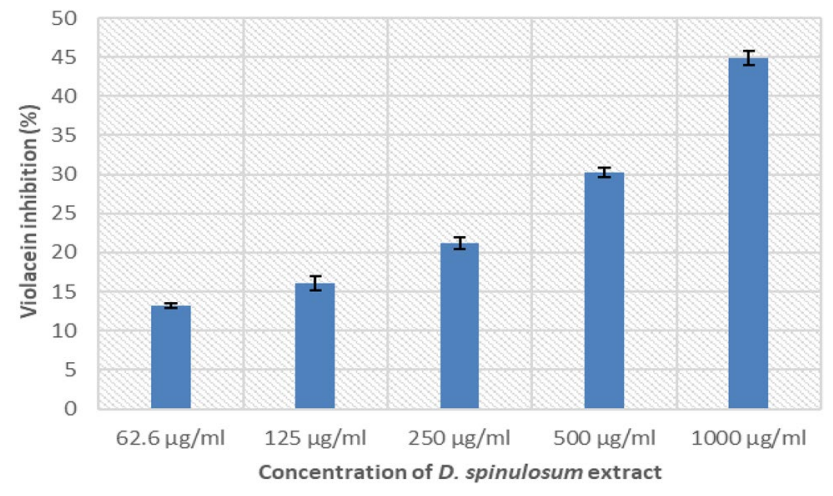

Figure 6. A chart showing a concentration-dependent inhibitory effect of DSE on violacein pigment production by C. violaceum (ATCC 12,472).
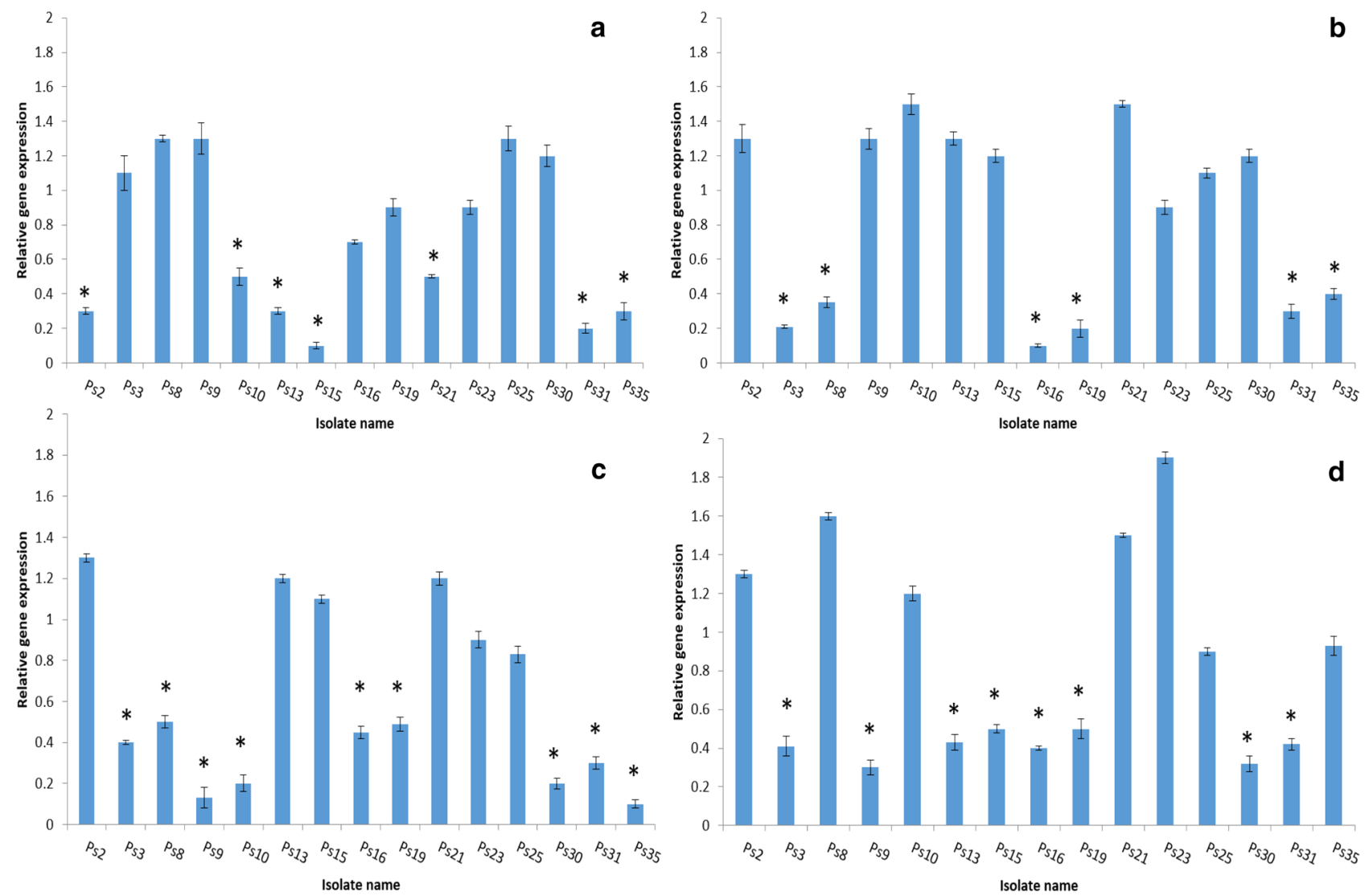

Figure 7. The relative expression of the quorum sensing genes: (a) lasI, (b) lasR, (c) rhlI, (d) rhlR of the tested $P$. aeruginosa isolates after treatment with DSE, ${ }^{*}$ indicates the changes in gene expression more than twofold.

Quantitative RT-PCR. The relative expression of las $\mathrm{I}, l a s \mathrm{R}, r h l \mathrm{I}, r h l \mathrm{R}$, and $n d v \mathrm{~B}$ genes was studied using qRT-PCR in 15 P. aeruginosa isolates (which exhibited a reduction in biofilm formation by the crystal violet test) for better comprehension of the effect of DSE on both QS and biofilm formation as shown in Figs. 7 and 8.

In vivo biofilm inhibition assay:. Naked eye examination of the burned skin revealed that the skin area of the control (group I) showed no apparent change. In group II (subgroup IIA), the burned area was partly covered with a brown dissected scab with exudate formation, and the size of the wound did not exhibit an apparent change (Fig. 9A). After 11 days of burn induction (subgroup IIB), the burned area was covered entirely by scab, and some areas showed necrosis. The size of the wound was nearly the same as in the previous subgroup IIA (Fig. 9B).

In group III (subgroup IIIA), the burned area appeared reddish in colour with less redness around it compared to group II. Additionally, it was dry with neither exudate nor necrosis. There was no scab, and the wound size 


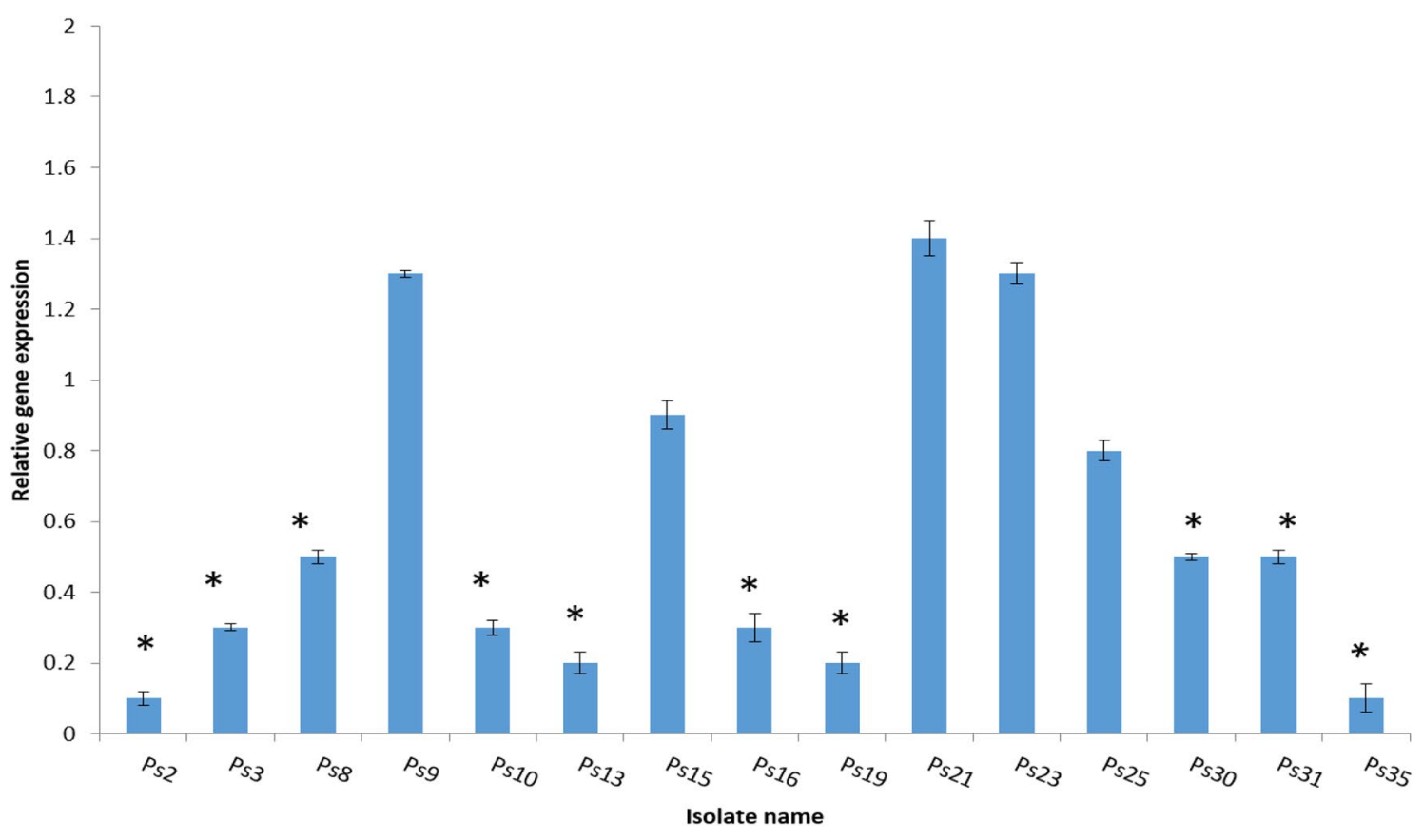

Figure 8. The relative expression of the biofilm gene of the tested $P$. aeruginosa isolates after treatment with DSE, ${ }^{*}$ indicates the changes in gene expression more than twofold.
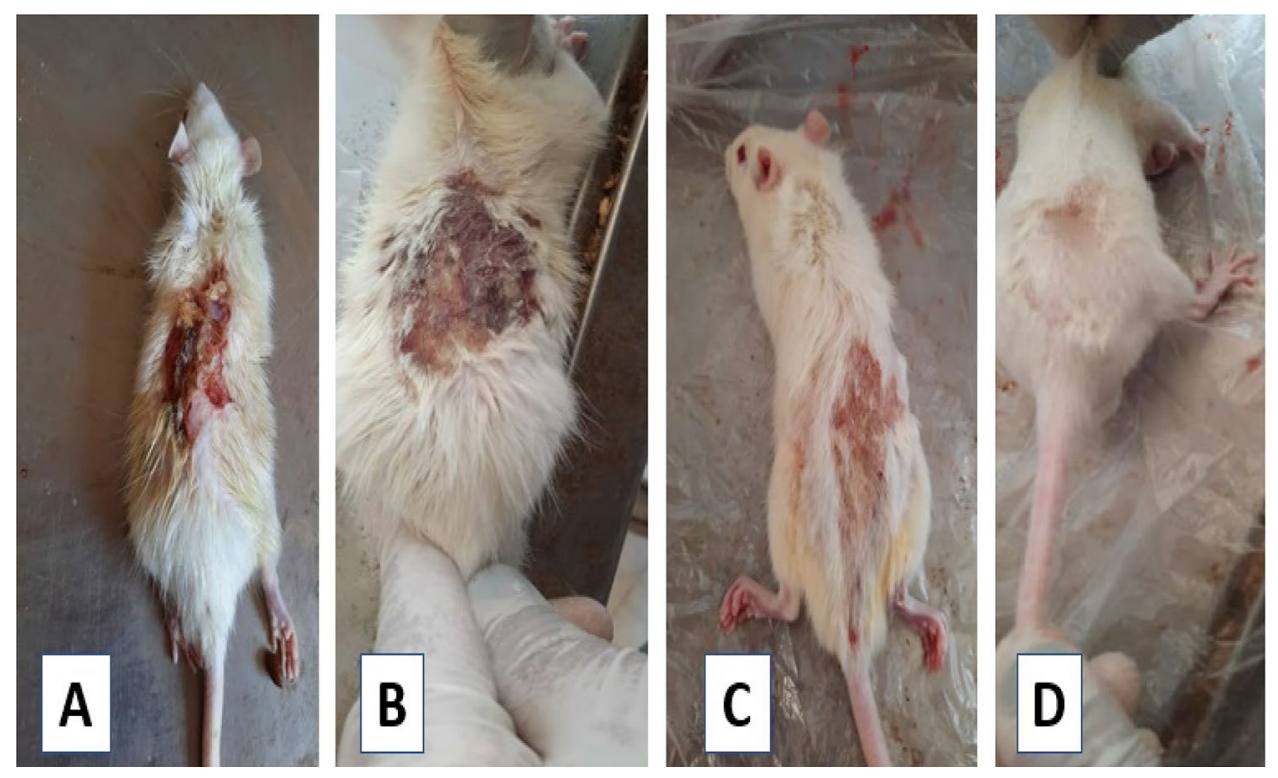

Figure 9. Photographs showing the burned skin of: (A) subgroup IIA: the burned area was clearly delineated from the adjacent skin with eschar formation (a collection of dead tissues). Additionally, there was an exudate on the wound's surface. (B) Subgroup IIB showing wound discoloration and necrosis of the eschar. (C) Subgroup IIIA showing a red burned area with no scab formation. (D) Subgroup IIIB, the burned area was markedly smaller in size and the edges were showing epidermal coverage and hair regrowth.

was apparently smaller than that of the burn model group II (Fig. 9C). Eleven days after the treatment with DSE (subgroup IIIB), the burned area was markedly smaller. The edges showed healing as represented by coverage by the epidermis with hair (Fig. 9D).

Examination with hematoxylin and eosin $(\mathrm{H} \& \mathrm{E})$ using a brightfield microscope revealed that the skin sections of the control group had two layers of skin: the epidermis and dermis. The epidermis consisted of squamous keratinized epithelium that was stratified, and the dermis consisted of connective tissue. It was divided into two 


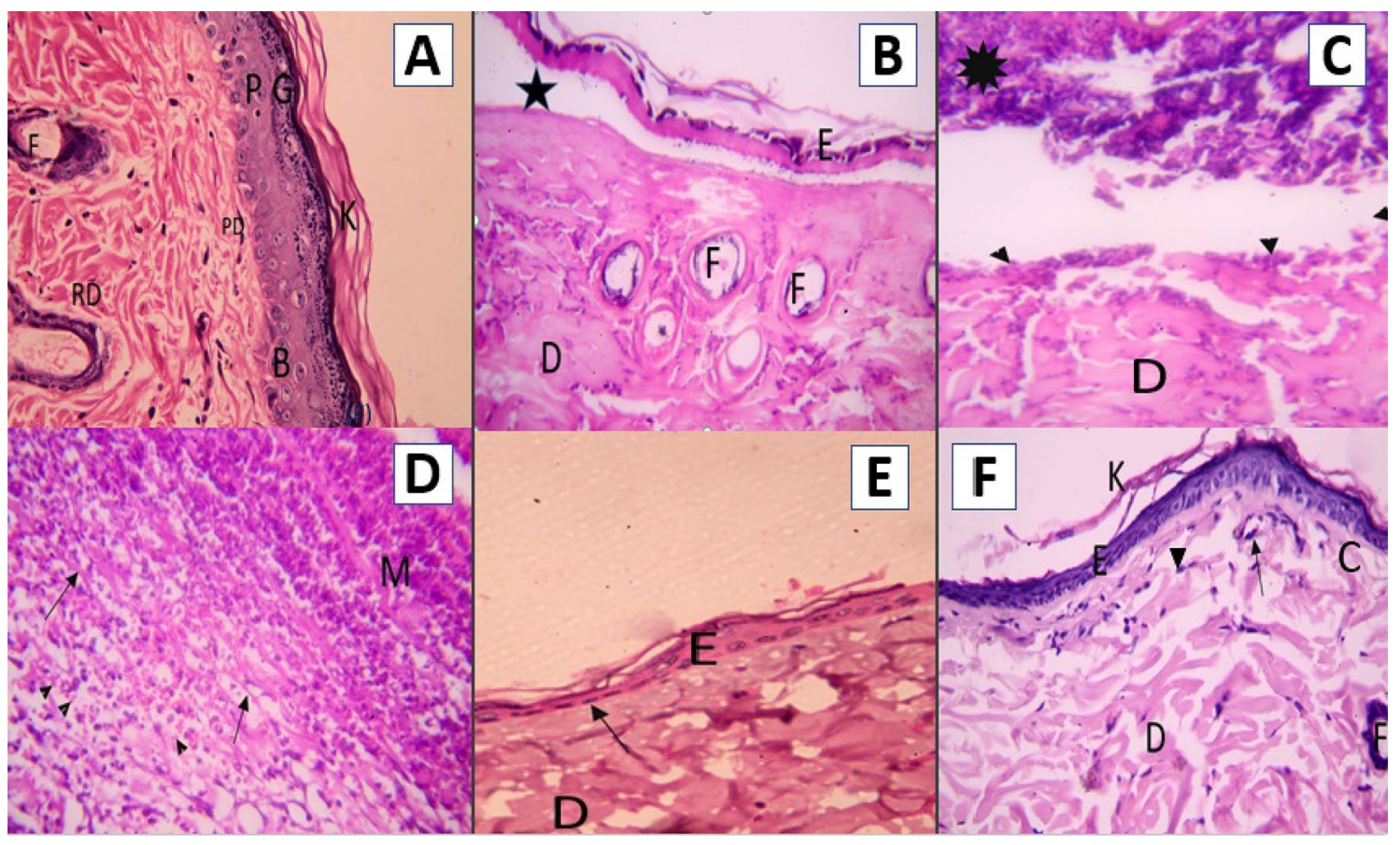

Figure 10. Photomicrographs of a section in the rat's skin of: (A) the control group, demonstrating basal layer (B), prickle cell layers (P), granular layers with basophilic granules $(\mathrm{G})$, and basket weave appearance of the horny layers $(\mathrm{K})$ of the epidermis. Moreover, hair follicles $(\mathrm{F})$ and fine collagen fibers were noticed in the papillary dermis (PD) in addition to thick fibers in the reticular dermis (RD) $(400 \times)$. (B) Group IIA illustrating thinning and denudation of epidermis (E) leaving wide space $\left(^{*}\right)$ between epidermis and dermis. The dermis contained thick deeply acidophilic and fused denatured collagen fibers (D). A damage of the hair follicles (F) was noticed leaving empty spaces $(400 \times)$. (C) Group IIB exposing loss of epidermis (filled triangle) and presence of eschar $\left({ }^{*}\right)$. The dermis contained inflammatory cells and coagulated collagen fibers $(400 \times)$. (D) Group IIB displaying deep dermis containing mononuclear inflammatory cells (M), extravasated RBCs (filled triangle), and fine collagen fibers in between $(\uparrow)(400 \times)$. (E) Group IIIA illustrating regenerated thin epidermis and flattening of the nuclei of the basal layers $(\uparrow)$. The underlying dermis contained fused hypocellular collagen fibers (D) $(400 \times)$. (F) Group IIIB illustrating an apparent increase in the thickness of the epidermis. Overcrowded basal basophilic low columnar cells of stratum basale and keratin layer $(\mathrm{K})$ were revealed. The underlying papillary dermis showed parallel fine collagen fibers (C), flat nuclei of fibroblasts (filled triangle), and blood vessels $(\uparrow)$. The reticular dermis contained thick collagen fibers (D) and hair follicle (F) $(400 \times)$.

layers without a sharp demarcation: a superficial thin papillary layer and a deep thick reticular layer. Hair follicles were found in the dermis (Fig. 10A).

The H\&E examination of thin skin sections of group IIA revealed an exfoliated upper part of the epidermis. The basal layer cells of the epidermis appeared flattened, and the collagen fibers in the upper dermis appeared hypocellular. Moreover, the collagen fibers appeared deeply acidophilic and fused with loss of the distinction between the collagen fibers. Skin appendages such as hair follicles and associated sebaceous glands were damaged, leaving empty spaces (Fig. 10B). The H\&E examination of thin skin sections of group IIB showed an epidermal loss, and a scab was formed covering the whole wounded area. The scab showed a deeply acidophilic structure composed of fine fibers and cells. The collagen fibers in the upper dermis appeared hypocellular and deeply acidophilic (Fig. 10C). The deep part of the dermis contained extravasated RBCs, mononuclear inflammatory cellular infiltration, and loose fine collagen fibers (Fig. 10D).

Examination of H\&E thin skin sections of group IIIA revealed preservation of a thin epidermis. The epidermis consisted of one layer of flattened keratinocytes with flat nuclei laid on a straight basement membrane. The underlying dermis presented thick and fused collagen fibers (Fig. 10E). H\&E staining of group IIIB stained sections revealed epidermal reepithelization, which appeared thick and consisted of stratified squamous epithelium with a thin coating of keratin. The epidermis was relatively thicker than that of the previous subgroup but still thinner than that of the control group, and it showed recesses of the hair follicles. The papillary layer of the dermis was more cellular and had numerous fibroblasts, capillaries, and fine collagen fibers. The reticular dermis revealed large aggregates of collagen bundles that contained thick collagen fibers (Fig. 10F).

SEM examination of thin skin sections from the control group revealed that the epidermis' outer layer (stratum corneum) had a tough coating made up of overlapping layers of dead skin cells (Fig. 11A).

Examination of SEM of thin skin sections of group IIB showed a marked increase in the aggregates like structures formed by P. aeruginosa bacteria to a degree higher than that of group IIA. These aggregates, like structures, masked the skin's outer surface and extended deeply into the dermis (Fig. 11B,C). 


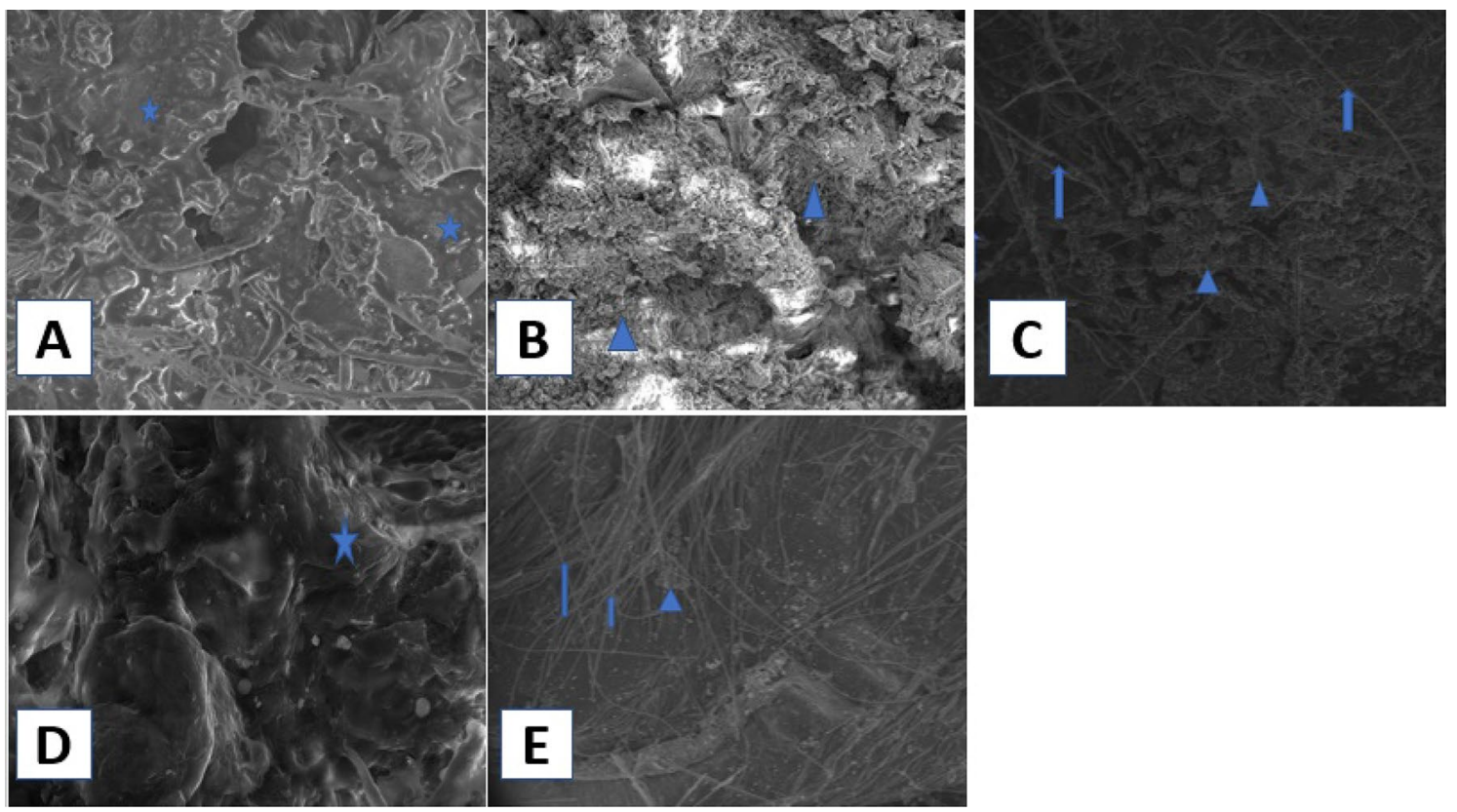

Figure 11. Scanning electron micrograph of the surface layer of the rat's skin of $(\mathbf{A})$ the control group showing that the epidermis (stratum corneum) had layers of overlapped dead skin cells $\left(^{*}\right)(2500 \times)$. (B) Group IIB showing that the outer layer of the stratum corneum studded with abundant numbers of $P$. aeruginosa bacteria (filled triangle) masking its structure. $(2500 \times)$. (C) Group IIB showing collagen fibers $(\uparrow)$ of the dermis with abundant numbers of $P$. aeruginosa bacteria making aggregates like structures (filled triangle) $(1000 \times)$. (D) Group IIIB, showing nearly normal stratum corneum $\left(^{*}\right)$ comparable to the control group $(2500 \times)$. (E) Group IIIB showing the collagen fibers $(\uparrow)$ of the dermis with few numbers of $P$. aeruginosa bacteria making aggregates like structures (filled triangle) in between $(1000 \times)$.

Examination of SEM of thin skin sections of group IIIB showed a marked reduction of $P$. aeruginosa bacteria on the skin's outer surface, with the appearance of nearly normal stratum corneum to a degree higher than that of group IIIA. The dermis also showed a few aggregates of $P$. aeruginosa bacteria in between collagen fibers (Fig. 11D,E).

Phytochemical constituents of DSE. Figure 12 displays the HPLC chromatogram for the identified flavonoids and phenolic compound in DSE. The abundant phenolic compounds in ug/g were ellagic acid (56.20), gallic acid (25.98), vanillin (14.69), methyl gallate (9.98), and chlorogenic acid (9.33), while the identified flavonoid compounds were naringenin (2183.67), apigenin (10.46), kaempferol (0.88), rutin (0.93), and catechin (0.01) (Table 3).

Cytotoxicity assay. The sulforhodamine B (SRB) assay was used to determine if DSE was cytotoxic to the human skin fibroblast (HSF) cell line ${ }^{8,9}$. DSE was compared to doxorubicin (a positive control), which had a halfmaximal inhibitory concentration $\left(\mathrm{IC}_{50}\right.$ ) of $4.36 \pm 0.52 \mu \mathrm{g} / \mathrm{ml}$, and DSE had an $\mathrm{IC}_{50}$ of $9.4 \pm 3.3 \mu \mathrm{g} / \mathrm{ml}$ against the HSF cell line as shown in Fig. 13.

\section{Discussion}

Recently, natural products have been regarded as a vital source for detecting many new therapeutic compounds ${ }^{10}$. D. spinulosum exhibited a variety of promising biological activities, including cytotoxic, antioxidant, and antimicrobial potential. This motivated us to undertake this study to search for an alternative effective natural source. Bacteria that are capable of forming biofilms are resistant to many antibiotics. This issue resulted in difficulty in curing biofilm-related infections ${ }^{11}$. It has been established that such bacteria depend mainly on two related phenomena: QS and biofilm formation ${ }^{12}$. The formation of biofilms by pathogenic P. aeruginosa isolates is mainly controlled by QS regulatory genes. Thus, anti-quorum sensing substances are usually investigated for inhibition of biofilm formation ${ }^{13}$. It is found that the commercially available anti-quorum sensing compounds could increase the in vitro and in vivo susceptibility of bacteria embedded in biofilms to antibiotics ${ }^{14}$.

In the current study, the anti-quorum sensing and anti-biofilm activities of DSE were investigated against $P$. aeruginosa clinical isolates. The MIC values of DSE were determined, and they ranged from 250 to $1000 \mu \mathrm{g} / \mathrm{ml}$. The impact of DSE on CSH, EPS quantity, biofilm formation, metabolic activity using MTT, biofilm morphology, and pigment production by C. violaceum (ATCC 12472) was assessed at sub-inhibitory concentrations ( 0.5 MIC values, i.e., at concentrations ranging from 125 to $500 \mu \mathrm{g} / \mathrm{ml}$ ) to exclude the effect of DSE on bacterial growth. In addition, its impact on the relative gene expression of the QS and biofilm genes was investigated. 


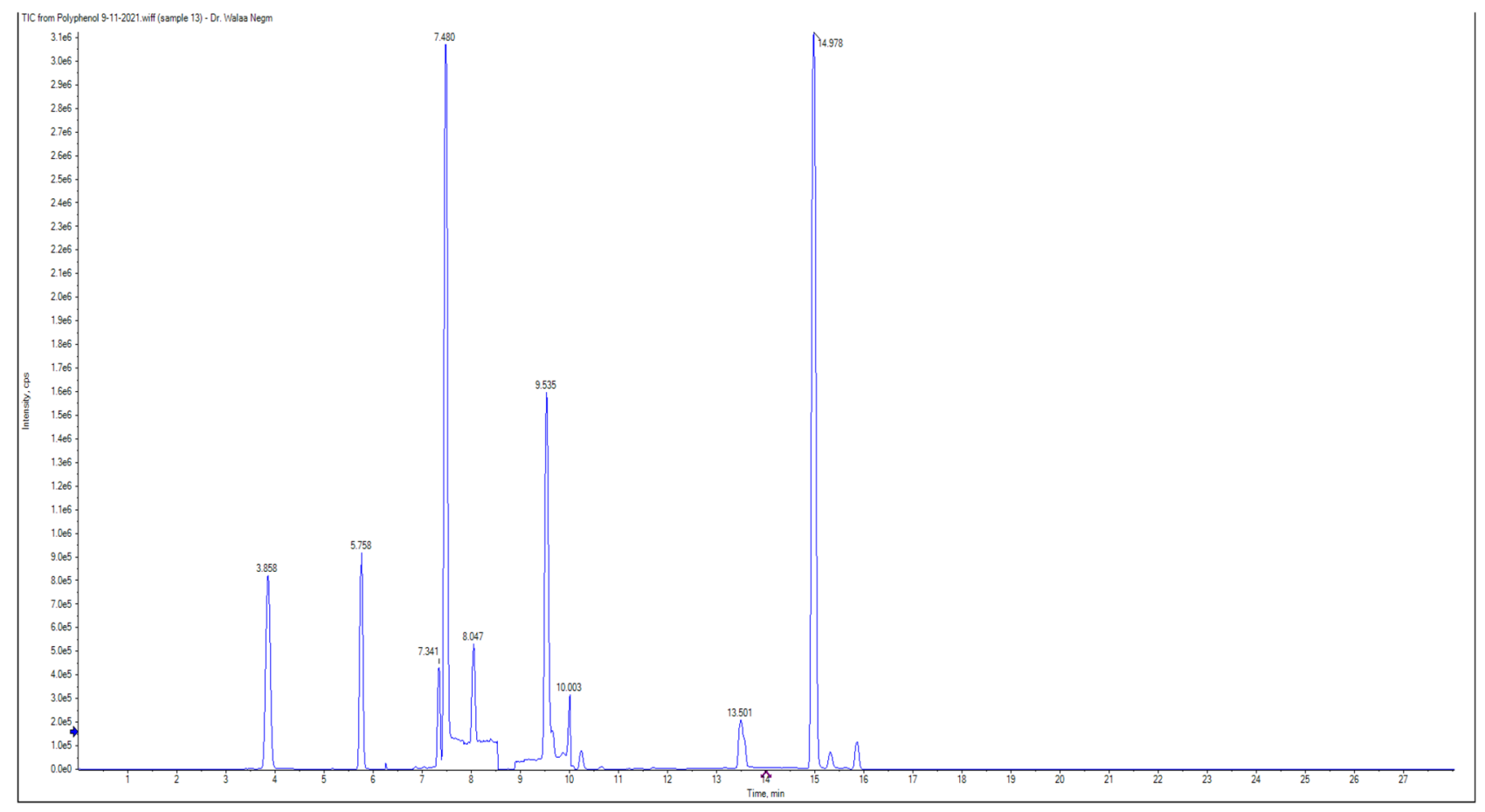

Figure 12. HPLC chromatogram of DSE.

\begin{tabular}{|l|l|}
\hline Compounds & Samples (conc.ug/g) \\
\hline Phenolic & 56.20 \\
\hline Ellagic acid & 25.98 \\
\hline Gallic acid & 14.69 \\
\hline Vanillin & 9.98 \\
\hline Methyl gallate & 9.33 \\
\hline Chlorogenic acid & 4.70 \\
\hline O-coumaric acid & 3.20 \\
\hline Ferulic acid & 2.02 \\
\hline Cinnamic acid & 1.35 \\
\hline Syringic acid & 0.67 \\
\hline Caffeic acid & ND \\
\hline 3,4-Dihydroxybenzoic acid & \multicolumn{2}{|l}{} \\
\hline Flavonoid & 2183.67 \\
\hline Naringenin & 10.46 \\
\hline Apigenin & 0.93 \\
\hline Rutin & 0.88 \\
\hline Kaempferol & 0.01 \\
\hline Catechin & ND \\
\hline Querectin & ND \\
\hline Hesperetin & ND \\
\hline Myricetin & ND \\
\hline Daidzein & ND \\
\hline Luteolin & \multicolumn{2}{|l|}{} \\
\hline
\end{tabular}

Table 3. Chemical composition analysis of phenolic and flavonoid compounds of DSE by HPLC.

The hydrophobic properties of the bacterial surfaces have a significant role in the bacterial adhesion to various surfaces in addition to the penetration of the host tissues. The hydrophobicity of bacterial surfaces could be measured by calculating $\mathrm{HI}^{15}$. We investigated the impact of DSE on CSH of the tested isolates, and a significant reduction $(\mathrm{p}<0.05)$ in the values of $\mathrm{HI}$ was noticed in $45.7 \%$ of the tested isolates after treatment with DSE. 


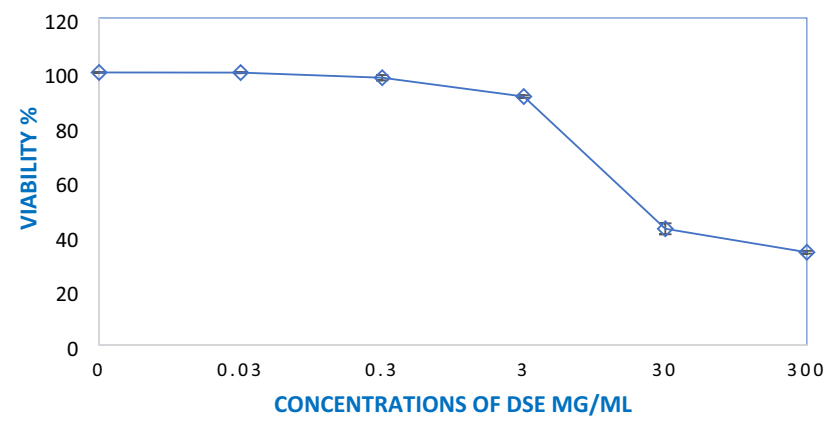

Figure 13. SRB cytotoxicity assay of DSE against HSF normal cell line, after incubation period of $72 \mathrm{~h}$. Different concentrations of $0.03,0.3,3,30$ and $300 \mu \mathrm{g} / \mathrm{mL}$ of DSE were used. IC $_{50 \mathrm{~s}}$ values were expressed as mean $\pm \mathrm{SD}$ of three performed assays.

Polysaccharides present in the biofilm matrix could provide various benefits to the bacterial cells embedded in biofilms, like adhesion and protection. They can act like glue, which permits the bacterial cells to adhere to each other as well as different surfaces. Moreover, polysaccharides could protect the cells in biofilms from desiccation and immune effectors ${ }^{16}$. Herein, we found that DSE exhibited a significant reduction $(\mathrm{p}<0.05)$ in the extracellular polysaccharides' quantity in $51.4 \%$ of $P$. aeruginosa isolates. The primary mechanism for such a reduction in EPS production after treatment with DSE needs further investigation.

There are two critical steps in biofilm production. The first step involves bacterial adhesion to different surfaces, which provides the groundwork for further biofilm development.

The second step involves the interactions between cells. At this stage, bacteria form microcolonies to construct a multilayer structure for biofilm development ${ }^{17}$. In the current study, the biofilm inhibition by DSE was evaluated using the crystal violet test. DSE decreased the percentage of $P$. aeruginosa isolates strongly and moderately producing biofilms from 77.1 to $34.3 \%$. Determination of CFU by agar plating is considered as the gold standard method for quantification of biofilm ${ }^{18}$. The main principle of this test is to quantify the living bacterial cells using an agar plate as they grow forming colonies that could be counted ${ }^{19}$. There was a significant reduction in the number of $\mathrm{CFU} / \mathrm{ml}$ in $34.3 \%$ of the isolates after treatment with DSE.

MTT assay was used to detect the effect of DSE on the viability of bacteria embedded in the biofilm. Viable bacterial cells with active metabolism will have the capability to convert MTT into formazan (purple colour) with an absorbance of $550 \mathrm{~nm}$. On the other hand, dead bacterial cells lose this capability. So, purple colour formation is a marker for viable cells only ${ }^{20}$. A non-significant change $(p>0.05)$ in the bacterial cells' viability was observed after treatment with DSE. To better understand the effect of DSE on biofilm formation by P. aeruginosa isolates, biofilm morphology was inspected using a compound bright field microscope and SEM. Microscopical examination confirmed DSE's biofilm inhibitory action against the tested isolates, as a significant reduction in the biofilms formed by $P$. aeruginosa isolates was observed after treatment with DSE.

Violacein is a dark purple indole derivative agent. Its production is essential for QS and hence biofilm formation. A reference strain, C. violaceum (ATCC 12472), is known for its ability to produce violacein, and thus, it is widely utilized for QS studies ${ }^{21}$. DES showed an anti-quorum sensing activity against C. violaceum (ATCC 12472 ) as it inhibited violacein production in a concentration-dependent manner.

qRT-PCR was utilized to inspect the impact of DSE on QS and biofilm formation genes in 15 P. aeruginosa isolates. Our results revealed that treatment with DSE decreased the expression of lasI, lasR, $r h l \mathrm{I}, r h l \mathrm{R}$, and $n d v \mathrm{~B}$ genes in $46.67 \%, 40 \%, 60 \%, 53.33 \%$, and $66.67 \%$ of the selected $P$. aeruginosa isolates, respectively.

The current study produced a partial thickness skin burn injury in rat groups II and III by scalding with hot water $\left(99^{\circ} \mathrm{C}\right)$ for $3 \mathrm{~s}^{22}$. Moreover, a mould was created to restrict the burn injury to a small uniform area of $1.1 \%$ of the total body surface area in the back to avoid shock and the death of rats ${ }^{23}$. Examination of group II (burn model) sections stained by H\&E showed a range of epidermal thinning, exfoliation, and necrosis. This came per Tanaka et al. ${ }^{24}$. In addition, Yang et al. ${ }^{25}$ found that the skin epidermis in deep second-degree burns was almost entirely dissected from the underlying dermis.

Meanwhile, the underlying dermis in the present study showed collagen denaturation in the form of swollen, fused, and closely packed collagen fibers. Similarly, Park et al. ${ }^{26}$ noticed that when the skin was thermally damaged, the fibers had a glass-like appearance from the dense coagulation of collagen. On the other hand, Tanaka et al. ${ }^{24}$ detected a loss of boundaries between collagen fibers and attributed this to water leakage from capillaries, causing edema and fusion of collagen fibers. The hair follicles with their associated glands were completely damaged in group II. Younan et al..$^{27}$ detected the same finding.

SEM examination of group II showed biofilm formation. Chu et al. ${ }^{26}$ stated that owing to the ability of $P$. aeruginosa to create biofilms on both biotic and abiotic surfaces within hours, and it could form biofilms within the burn eschar (a collection of dead tissues). These biofilms could serve as a nidus for long-term wound infection and transplant failure. In addition, $P$. aeruginosa also expresses various proteases, including collagenase, which may aid it in entering burned skin ${ }^{22}$. Furthermore, the biofilm infection causes an inflammatory response in the local burn skin infected with $P$. aeruginosa, as evidenced by increased circulating neutrophils and increased myeloperoxidase activity. The inflammatory cells seen in $\mathrm{H} \& \mathrm{E}$-stained tissue sections mainly were neutrophils. 
Meanwhile, in group III, treatment with DSE resulted in epidermal regeneration, which was started by the migration of cells from the basal layer of adjacent healthy skin. DSE significantly improved wound contracture and healing. Furthermore, it appeared to improve the healing process by regenerating the epidermis and reducing inflammatory cell infiltration associated with collagen fiber deposition compared to the infected group. It also showed nearly intact hair follicles. This comes in agreement with Negm et al. ${ }^{7}$, who stated that DSE showed higher activity against Gram-negative bacteria, like E. coli and P. aeruginosa, than Gram-positive bacteria.

\section{Materials and methods}

Bacteria. Thirty-five P. aeruginosa isolates were collected from Tanta University hospitals. These clinical isolates were subjected to microscopical examination, and they were identified using standard biochemical tests according to MacFaddin ${ }^{28}$. Pseudomonas aeruginosa ATCC 27853 was utilized as the standard isolate.

Plant material. Dioon spinulosum Dyer Ex Eichler leaves were selected from El Abd Garden in Giza city on January 14th, 2017. The permission for plant collection was obtained from the landowner, Mr. Rabea Sharawy. Then, Dr. Esraa Ammar (a plant ecology lecturer at Botany Department, Faculty of Science, Tanta University) and Mr. Rabea Sharawy (an agronomist and palm researcher were) kindly identified the plant. A voucher specimen number: PGG-002 was deposited at Pharmacognosy Department herbarium, Faculty of Pharmacy, Tanta University.

One kilogram of shade-dried powdered leaves of D. spinulosum was extracted by cold maceration with $\mathrm{MeOH}$ $(3 \mathrm{~L} \times 3,48 \mathrm{~h}$ each $)$ then concentrated under vacuum using a rotary evaporator at $45^{\circ} \mathrm{C}$ to yield the crude extract $(87.2 \mathrm{~g})$ that were used for biological investigations.

Chemicals. All the utilized chemicals were of analytical grade, obtained from Merck (New Jersey, United States). The standard phenolic and flavonoid compounds used were gallic acid, methyl gallate, chlorogenic acid, vanillin, caffeic acid, syringic acid, ferulic acid, ellagic acid, 3,4-dihydroxybenzoic acid, $O$-coumaric acid, cinnamic acid, apigenin, rutin, myricetin, catechin, quercetin, naringenin, hesperetin, daidzein, luteolin, and kaempferol.

Determination of MICs of DSE against the tested isolates. The MICs of DSE were determined by the broth microdilution method ${ }^{29}$. Each plate contained a positive control (untreated bacteria) and negative control (non-inoculated well).

All the following experiments were performed before and after treatment of the tested isolates with subinhibitory concentrations of DSE (0.5 MIC values).

Determination of CSH. It was determined in the tested isolates before and after treatment with DSE (with concentrations of $0.5 \mathrm{MIC}$ values that ranged from 125 to $500 \mu \mathrm{g} / \mathrm{ml}$ ) according to the method previously explained $^{30}$. After centrifugation of the bacterial suspensions, the pellets were resuspended in phosphate urea magnesium sulfate buffer (PUM buffer, $\mathrm{pH}$ 6.9). Then, several volumes of $n$-hexane $(0.3,0.9,1.2$, and $1.8 \mathrm{ml}$ ) were added to $4.8 \mathrm{ml}$ of each bacterial suspension in the PUM buffer and vortexed. The suspension was allowed to stand for complete phase separation. Finally, the absorbance of the bacterial isolates that remained in the aqueous phase was measured at $540 \mathrm{~nm}$. The HI was determined as follow:

$$
H I=(A 540 \text { control }- \text { A540 test }) / A 540 \text { control }
$$

Quantification of EPS. EPS extraction and quantification were carried out as previously described ${ }^{31}$. Briefly, the tested isolates were overnight grown at $37^{\circ} \mathrm{C}$ in Luria-Bertani (LB) broth with (treated isolates) and without (untreated isolates) DSE (using concentrations ranging from 125 to $500 \mu \mathrm{g} / \mathrm{ml}$ ). After incubation, they were centrifuged, and the pellets were resuspended in phosphate-buffered saline (PBS) buffer and centrifuged again. Then, ethyl alcohol was added to the supernatant with an equal volume and centrifuged. Finally, $1 \mathrm{ml}$ of the EPS solution was thoroughly mixed with an equal volume of cold $5 \%$ phenol plus $5 \mathrm{ml}$ concentrated sulfuric acid. The optical intensity (OD) of the produced red colour was measured at $490 \mathrm{~nm}$, and the percentages of inhibition of EPS were calculated.

In vitro biofilm inhibition assay. Biofilm formation was examined in the tested isolates before and after treatment with DSE (with concentrations ranging from 125 to $500 \mu \mathrm{g} / \mathrm{ml}$ ) using the crystal violet test ${ }^{32,33}$. The $\mathrm{OD}$ at $490 \mathrm{~nm}$ was measured using an ELISA reader (Sunrise Tecan, Grodig, Austria). The tested isolates were characterized into four groups based on their ODs as follows:

i. NBP: non-biofilm producer $(\mathrm{ODc}<\mathrm{OD}<2 \mathrm{ODc})$

ii. WBP: weak biofilm producer $(2 \mathrm{ODc}<\mathrm{OD}<4 \mathrm{ODc})$

iii. MBP: moderate biofilm producer $(4 \mathrm{ODc}<\mathrm{OD}<6$ ODc)

iv. SBP: strong biofilm producer $(6 \mathrm{ODc}<\mathrm{OD})$

The cut-off $\mathrm{OD}(\mathrm{ODc})$ is the mean OD plus $3 \mathrm{SD}$ of the negative control. 
Determination of CFU. The formed biofilms in the wells of the microtitration plates were washed twice with PBS so that the loosely attached cells were removed. Then, the biofilms were scraped off the wells through vigorous scraping using a pipette tip after adding $200 \mu \mathrm{PBS}$. They were then vortexed in order to homogenize the biofilm. After that, they were serially diluted, and $100 \mu \mathrm{l}$ from each dilution was plated on Muller-Hinton agar (MHA) plates. After overnight incubation, the CFU were counted ${ }^{18}$.

Estimation of the metabolic activity of biofilm by MTT assay. The MTT colorimetric assay was performed as previously described ${ }^{30,34}$. Briefly, the bacterial suspensions were overnight incubated with (treated isolates) and without (untreated isolates) DSE (using concentrations ranging from 125 to $500 \mu \mathrm{g} / \mathrm{ml}$ ). To each well of the microtitration plate, $150 \mu \mathrm{l}$ of PBS and $50 \mu \mathrm{l}$ of MTT solution were added. Then, the MTT solution was withdrawn after $2 \mathrm{~h}$, and $150 \mu \mathrm{l}$ of dimethyl sulphoxide (DMSO) was added instantly as a solubilizing agent. Finally, the absorbance was measured at a wavelength of $550 \mathrm{~nm}$ by an ELISA reader (Sunrise Tecan, Grodig, Austria).

Examination of biofilm morphology. The effect of DSE was tested against biofilm formation by $P$. aeruginosa isolates on glass surfaces as previously described ${ }^{35}$. Biofilm formed by P. aeruginosa with (treated isolates) and without (untreated isolates) DSE (using concentrations ranging from 125 to $500 \mu \mathrm{g} / \mathrm{ml}$ ) was visualized by a compound bright field microscope (Labomed, California, America) using $40 \times$ magnification after staining with crystal violet.

Scanning electron microscope (SEM). SEM was used to examine the bacterial biofilms formed on the surfaces of cover glass with (treated isolates) and without (untreated isolates) DSE (using concentrations ranging from 125 to $500 \mu \mathrm{g} / \mathrm{ml}$ ) as described previously ${ }^{36,37}$, and examined using an S-3400N scanning electron microscope (Hitachi, Tokyo, Japan).

Quantification of inhibition of violacein production. It was performed as described by Ganesh and $\mathrm{Rai}^{31}$. DSE (with concentrations ranging from 62.5 to $1000 \mu \mathrm{g} / \mathrm{ml}$ ) was added to a $10 \mu \mathrm{l}$ suspension of C. violaceum (ATCC 12472) in LB broth and incubated overnight at $30^{\circ} \mathrm{C}$. Centrifugation was performed after incubation, and $500 \mu \mathrm{l}$ of DMSO was added to each pellet and vortexed vigorously till the extraction of violacein (purple colour). The extracted violacein $(200 \mu \mathrm{l})$ was transferred into a 96 well microtitration plate and quantified using an ELISA reader (Sunrise Tecan, Grodig, Austria) at $585 \mathrm{~nm}$. The control was the bacterial culture of $C$. violaceum in LB broth without the DSE.

qRT-PCR. The expression of 4 quorum sensing genes (lasI, lasR, rhlI, rhlR) $)^{38}$, and the biofilm gene (ndvB) were identified using qRT-PCR, and the $16 S$ rRNA gene was utilized as the housekeeping gene ${ }^{39}$. All the experiments were conducted in triplicate, and the results were expressed as mean \pm SD values. According to the manufacturer's instructions, after extraction of the total RNA, using the GeneJET RNA purification kit, K0731 (Thermo Scientific, Waltham, USA), it was retrotranscribed into cDNA by using a power cDNA synthesis kit (iNtRON Biotechnology, Seongnam, Korea). The utilized primers are shown in Table S1. The amplification was performed using the Power SYBR Green master mix (Thermo SCIENTIFIC, Waltham, USA) and the RotorGene Q 5plex apparatus (Qiagen, Hilden, Germany). The relative gene expression was calculated by using the $2^{-\Delta \Delta C t}$ method $^{40}$. Non-treated isolates were used as control samples (i.e., expression set to 1 ).

In vivo biofilm inhibition assay. All of the animals were purchased and grown at Ain Shams University's Medical Research Center. Twenty-five adult female albino rats of an average weight of 200-250 g were utilized. The animal experiment was carried out at the Ain Shams University Faculty of Medicine's Research Center Institute (MASRI). It was approved by the Faculty of Medicine, Ain Shams University Research Ethics Committee (FMASU REC) organized and run under the International Council on Harmonization (ICH) and Islamic Organization for Medical Science (IOMS) guidelines, as well as the US Office for Human Research Protections and US Code of Federal Regulations and is covered by Federal Wide Assurance N.FWA 00017585.

The Burn model. Intraperitoneal injection of $40 \mathrm{mg} / \mathrm{kg}$ pentobarbital sodium was used to anesthetize the rats $^{41}$. The dorsal hair of the rats was removed from an area of $4 \mathrm{~cm}^{2}$ in the middle of their backs, $3 \mathrm{~cm}$ away from the neck, first with clippers and then through the application of one depilatory cream. A mould was applied to the shaved area of the back of the rats. Hot water at $99{ }^{\circ} \mathrm{C}$ was poured into the mould for $3 \mathrm{~s}$ to induce a partialthickness burn ${ }^{22}$. The rats were divided into three groups:

Group I: consisted of 5 rats, which served as the control group.

Group II (inoculated untreated burn group): consisted of 10 rats. The same procedure was applied as previously described in the burn model; then, the burning surface was inoculated with $30 \mu$ of a suspension of $1 \times 10^{8}$ $\mathrm{CFU} / \mathrm{ml}$ of $P$. aeruginosa in the center of each wound. Then, a pipette tip was used to spread it to cover the entire burn area ${ }^{42}$. This group is further divided into:

Group IIA: consisted of 5 rats sacrificed 3 days after creating the inoculated burn.

Group IIB: consisted of 5 rats, sacrificed 11 days after creating the inoculated burn.

Group III (inoculated treated burn group): consisted of 10 rats. The same procedures were applied as in group

II, then a solution of DSE was applied daily to the burn area. This group is further divided into:

Group IIIA: consisted of 5 rats, sacrificed 3 days after creating the inoculated burn.

Group IIIB: consisted of 5 rats, sacrificed 11 days after creating the inoculated burn. 
Histological studies. Five micrometer paraffin sections were prepared and stained with H\&E and examined by a brightfield microscope to show the histological details ${ }^{43}$. Moreover, the burn wound surface-associated $P$. aeruginosa biofilms were examined using $\mathrm{SEM}^{43}$.

Analyses of phenolics and flavonoids by HPLC. An Agilent 1260 Infinity HPLC Series (Agilent, Santa Clara, CA, USA), equipped with a Quaternary pump and a Zorbax Eclipse Plus C18 column (100 $\mathrm{mm} \times 4.6 \mathrm{~mm}$ i.d.) (Agilent Technologies, Santa Clara, CA, USA), was operated at $30^{\circ} \mathrm{C}$. The separation was achieved using a ternary linear elution gradient with (A) HPLC grade water, $0.2 \% \mathrm{H}_{3} \mathrm{PO}_{4}(\mathrm{v} / \mathrm{v})$, (B) methanol, and (C) acetonitrile. The injectable volume was $20 \mu \mathrm{L}$. A VWD detector was set at $284 \mathrm{~nm}$ to identify the phenolic compounds in the DSE ${ }^{44,45}$.

Cytotoxicity assay. The SRB test was used to measure HSF cell viability ${ }^{8,9}$. Aliquots of $100 \mu$ cell suspension $\left(5 \times 10^{3}\right.$ cells) were incubated in full medium for $24 \mathrm{~h}$ in 96 -well plates. A different aliquot of $100 \mu \mathrm{l}$ medium and the DSE at varied doses was utilized to treat the cells. The cells were fixed by replacing the medium with 150 $\mu \mathrm{l}$ of $10 \%$ trichloroacetic acid (TCA) and incubated for $60 \mathrm{~min}$ at $4{ }^{\circ} \mathrm{C}$ after $72 \mathrm{~h}$ of exposure to DSE. The HSF cells were rinsed five times with distilled water, and liquors of $70 \mu \mathrm{l} \mathrm{SRB}$ solution $(0.4 \% \mathrm{w} / \mathrm{v})$ were added and kept in a dark place for $10 \mathrm{~min}$ at room temperature. Plates were washed three times with $1 \%$ acetic acid and left to dry overnight in the air. Finally, $150 \mu \mathrm{l}$ of Tris base solution $(10 \mathrm{mM})$ was added to dissolve the protein-bound $\mathrm{SRB}$ stain, and the absorbance was measured at $540 \mathrm{~nm}$ using an ELISA reader.

Statistical analysis. All the performed assays were carried out in triplicates, and the results were presented as mean \pm SD. The statistical significance of the results was determined by one-way ANOVA using SPSS software (IBM, USA), and only results with a $\mathrm{p}<0.05$ were considered significant. Statistical analysis:

Ethical approval. All experiments were performed in accordance with the relevant guidelines and regulations. All experiments and protocols were approved by Ain Shams University and Tanta university. The animal experiment was carried out at the Ain Shams University Faculty of Medicine's Research Center Institute (MASRI). The animal experiments were approved by the FMASU REC organized and run under the International Council on Harmonization (ICH) and Islamic Organization for Medical Science (IOMS) guidelines, as well as the US Office for Human Research Protections and US Code of Federal Regulations and is covered by Federal Wide Assurance N.FWA 00017585. All reported methods are in accordance with ARRIVE guidelines.

\section{Conclusion}

The current study revealed the potential in vitro and in vivo anti-biofilm and anti-quorum sensing activities of DSE as it exhibited efficient activity against $P$. aeruginosa clinical isolates. To our knowledge, this is the first time to report the ability of DSE to reduce biofilm formation by $P$. aeruginosa via downregulation of quorum sensing genes. This finding could help in the reduction of our significant dependence on antibiotics. Moreover, this could help us efficiently handle the biofilm-related infections caused by such opportunistic pathogens. Thus, further studies are necessary to examine the possible inhibitory effects of DSE on biofilms formed by other pathogens. In addition, preclinical and clinical studies are required to enable its practical implementation in managing $P$. aeruginosa biofilm-related infections.

\section{Data availability}

The data supporting this study are available upon request.

Received: 12 September 2021; Accepted: 30 November 2021

Published online: 07 January 2022

\section{References}

1. El-Sayed, N. R., Samir, R., Abdel-Hafez, J. M. \& Ramadan, M. A. Olive leaf extract modulates quorum sensing genes and biofilm formation in multi-drug resistant Pseudomonas aeruginosa. Antibiotics 9, 526 (2020).

2. Su, S. \& Hassett, D. J. Anaerobic Pseudomonas aeruginosa and other obligately anaerobic bacterial biofilms growing in the thick airway mucus of chronically infected cystic fibrosis patients: An emerging paradigm or "Old Hat"?. Expert Opin. Ther. Targets 16, 859-873 (2012).

3. Sugano, M. et al. Potential effect of cationic liposomes on interactions with oral bacterial cells and biofilms. J. Liposome Res. 26, 156-162 (2016).

4. Wagner, S. et al. Novel strategies for the treatment of Pseudomonas aeruginosa infections. J. Med. Chem. 59, 5929-5969 (2016).

5. Lee, J. \& Zhang, L. The hierarchy quorum sensing network in Pseudomonas aeruginosa. Protein Cell 6, 26-41 (2015).

6. Negm, W., Abo El-Seoud, K., Kabbash, A. \& El-Aasr, M. Investigation of the biological activity some gymnosperm plants belong to cycadales order. J. Adv. Med. Pharmaceut. Res. 1, 9-13 (2020).

7. Negm, W. A., Abo El-Seoud, K. A., Kabbash, A., Kassab, A. A. \& El-Aasr, M. Hepatoprotective, cytotoxic, antimicrobial and antioxidant activities of Dioon spinulosum leaves Dyer Ex Eichler and its isolated secondary metabolites. Nat. Prod. Res. 1, 1-11 (2020).

8. Skehan, P. et al. New colorimetric cytotoxicity assay for anticancer-drug screening. JNCI 82, 1107-1112 (1990).

9. Allam, R. M. et al. Fingolimod interrupts the cross talk between estrogen metabolism and sphingolipid metabolism within prostate cancer cells. Toxicol. Lett. 291, 77-85 (2018).

10. Atanasov, A. G., Zotchev, S. B., Dirsch, V. M. \& Supuran, C. T. Natural products in drug discovery: Advances and opportunities. Nat. Rev. Drug Discovery 20, 200-216 (2021).

11. Sharma, D., Misba, L. \& Khan, A. U. Antibiotics versus biofilm: An emerging battleground in microbial communities. Antimicrob. Resist. Infect. Control 8, 1-10 (2019). 
12. Zhao, X., Yu, Z. \& Ding, T. Quorum-sensing regulation of antimicrobial resistance in bacteria. Microorganisms 8, 425 (2020).

13. Singh, V. K., Mishra, A. \& Jha, B. Anti-quorum sensing and anti-biofilm activity of Delftia tsuruhatensis extract by attenuating the quorum sensing-controlled virulence factor production in Pseudomonas aeruginosa. Front. Cell. Infect. Microbiol. 7, 337 (2017).

14. Jiang, Y., Geng, M. \& Bai, L. Targeting biofilms therapy: Current research strategies and development hurdles. Microorganisms 8, $1222(2020)$.

15. Krasowska, A. \& Sigler, K. How microorganisms use hydrophobicity and what does this mean for human needs?. Front. Cell. Infect. Microbiol. 4, 112 (2014).

16. Limoli, D. H., Jones, C. J. \& Wozniak, D. J. Bacterial extracellular polysaccharides in biofilm formation and function. Microbio. Spectrum 3, 29 (2015).

17. Olivares, E. et al. Clinical impact of antibiotics for the treatment of Pseudomonas aeruginosa biofilm infections. Front. Microbiol. 10, 2894 (2020).

18. Thieme, L. et al. Adaptation of the start-growth-time method for high-throughput biofilm quantification. Front. Microbiol. 2395 (2021).

19. Wilson, C. et al. Quantitative and qualitative assessment methods for biofilm growth: A mini-review. Res. Rev. J. Eng. Technol. 6 (2017).

20. Benov, L. Effect of growth media on the MTT colorimetric assay in bacteria. PLoS ONE 14, e0219713 (2019).

21. Kanelli, M. et al. Microbial production of violacein and process optimization for dyeing polyamide fabrics with acquired antimicrobial properties. Front. Microbiol. 9, 1495 (2018).

22. Brandenburg, K. S. et al. Development of Pseudomonas aeruginosa biofilms in partial-thickness burn wounds using a SpragueDawley rat model. J. Burn Care Res. 40, 44-57 (2019).

23. Tavares Pereira, D. d. S., Lima-Ribeiro, M. H. M., de Pontes-Filho, N. T., Carneiro-Leão, A. M. d. A. \& Correia, M. T. d. S. Development of animal model for studying deep second-degree thermal burns. J. Biomed. Biotechnol. 2012 (2012).

24. Tanaka, R. et al. In vivo visualization of dermal collagen fiber in skin burn by collagen-sensitive second-harmonic-generation microscopy. J. Biomed. Opt. 18, 061231 (2013).

25. Yang, Y., Zhang, W., Li, Y., Fang, G. \& Zhang, K. Scalded skin of rat treated by using fibrin glue combined with allogeneic bone marrow mesenchymal stem cells. Ann. Dermatol. 26, 289-295 (2014).

26. Park, B. H., Saxer, C. E., Srinivas, S. M., Nelson, J. S. \& de Boer, J. F. In vivo burn depth determination by high-speed fiber-based polarization sensitive optical coherence tomography. J. Biomed. Opt. 6, 474-479 (2001).

27. Younan, G. et al. The inflammatory response after an epidermal burn depends on the activities of mouse mast cell proteases 4 and 5. J. Immunol. 185, 7681-7690 (2010).

28. MacFaddin, J. Biochemical Tests for Identification of Medical Bacteria, Williams and Wilkins. Philadelphia, PA 113 (2000).

29. Wayne, A. Clinical and Laboratory Standards Institute; CLSI. 2017. Performance standards for antimicrobial susceptibility testing. 20th Informational Supplement. CLSI document (2017).

30. El-Banna, T., Abd El-Aziz, A., Sonbol, F. \& El-Ekhnawy, E. Adaptation of Pseudomonas aeruginosa clinical isolates to benzalkonium chloride retards its growth and enhances biofilm production. Mol. Biol. Rep. 46, 3437-3443 (2019).

31. Ganesh, P. S. \& Rai, V. R. Attenuation of quorum-sensing-dependent virulence factors and biofilm formation by medicinal plants against antibiotic resistant Pseudomonas aeruginosa. J. Tradit. Complement. Med. 8, 170-177 (2018).

32. Elekhnawy, E. A., Sonbol, F. I., Elbanna, T. E. \& Abdelaziz, A. A. Evaluation of the impact of adaptation of Klebsiella pneumoniae clinical isolates to benzalkonium chloride on biofilm formation. Egypt. J. Med. Hum. Genet. 22, 1-6 (2021).

33. Yang, H., Zhang, H., Wang, J., Yu, J. \& Wei, H. A novel chimeric lysin with robust antibacterial activity against planktonic and biofilm methicillin-resistant Staphylococcus aureus. Sci. Rep. 7, 1-13 (2017).

34. Trafny, E. A., Lewandowski, R., Zawistowska-Marciniak, I. \& Stępińska, M. Use of MTT assay for determination of the biofilm formation capacity of microorganisms in metalworking fluids. World J. Microbiol. Biotechnol. 29, 1635-1643 (2013).

35. Attallah, N. G. et al. Antibacterial activity of Boswellia sacra Flueck. Oleoresin extract against Porphyromonas gingivalis periodontal pathogen. Antibiotics 10, 859 (2021).

36. Attallah, N. G. M. et al. Elucidation of phytochemical content of Cupressus macrocarpa leaves: in vitro and in vivo antibacterial effect against methicillin-resistant Staphylococcus aureus clinical isolates. Antibiotics 10, 890 (2021).

37. Elekhnawy, E., Sonbol, F., Abdelaziz, A. \& Elbanna, T. An investigation of the impact of triclosan adaptation on Proteus mirabilis clinical isolates from an Egyptian university hospital. Braz. J. Microbiol. 1, 1-11 (2021).

38. Rajkumari, J. et al. Anti-quorum sensing and anti-biofilm activity of 5-hydroxymethylfurfural against Pseudomonas aeruginosa PAO1: Insights from in vitro, in vivo and in silico studies. Microbiol. Res. 226, 19-26 (2019).

39. Li, P.-J. et al. Effect of prolonged radiotherapy treatment time on survival outcomes after intensity-modulated radiation therapy in nasopharyngeal carcinoma. PLoS ONE 10, e0141332 (2015).

40. Livak, K. J. \& Schmittgen, T. D. Analysis of relative gene expression data using real-time quantitative PCR and the $2-\Delta \Delta C T$ method. Methods 25, 402-408 (2001).

41. Gaertner, D., Hallman, T., Hankenson, F. \& Batchelder, M. Anesthesia and analgesia for laboratory rodents, p 239-297. Anesthesia and analgesia in laboratory animals. London (UK): Elsevier (2008).

42. Andersson, M. Å., Madsen, L. B., Schmidtchen, A. \& Puthia, M. Development of an experimental ex vivo wound model to evaluate antimicrobial efficacy of topical formulations. Int. J. Mol. Sci. 22, 5045 (2021).

43. Brandenburg, K. S. et al. Formation of Pseudomonas aeruginosa biofilms in full-thickness scald burn wounds in rats. Sci. Rep. 9 , $1-12(2019)$.

44. Behiry, S. I. et al. Antifungal and antibacterial activities of Musa paradisiaca L. peel extract: HPLC analysis of phenolic and flavonoid contents. Processes 7, 215 (2019).

45. Ashmawy, N. A. et al. Eco-friendly wood-biofungicidal and antibacterial activities of various Coccoloba uvifera L. leaf extracts: HPLC analysis of phenolic and flavonoid compounds. BioResources 15, 4165-4187 (2020).

\section{Acknowledgements}

The authors would like to extend their sincere appreciation to Taif University Researchers Supporting Project number (TURSP-2020/309), Taif University, Taif, Saudi Arabia.

\section{Author contributions}

Conceptualization, E.E.; data curation, W.A.N. investigation, M.E.A.; methodology, E.E., W.A.N. and H.M.F.; project administration, A.A.; sources and software, E.E and W.A.N.; supervision, M.E.A. and A.A.; validation, G.E.B.; visualization, H.M.F.; writing-original draft, E.E., W.A.N. and H.M.F.; writing-review and editing, M.E.A., A.A., and G.E.B. All authors have read and agreed to the published version of the manuscript.

\section{Competing interests}

The authors declare no competing interests. 


\section{Additional information}

Supplementary Information The online version contains supplementary material available at https://doi.org/ 10.1038/s41598-021-03953-x.

Correspondence and requests for materials should be addressed to E.E. or W.A.N.

Reprints and permissions information is available at www.nature.com/reprints.

Publisher's note Springer Nature remains neutral with regard to jurisdictional claims in published maps and institutional affiliations.

(c) (i) Open Access This article is licensed under a Creative Commons Attribution 4.0 International License, which permits use, sharing, adaptation, distribution and reproduction in any medium or format, as long as you give appropriate credit to the original author(s) and the source, provide a link to the Creative Commons licence, and indicate if changes were made. The images or other third party material in this article are included in the article's Creative Commons licence, unless indicated otherwise in a credit line to the material. If material is not included in the article's Creative Commons licence and your intended use is not permitted by statutory regulation or exceeds the permitted use, you will need to obtain permission directly from the copyright holder. To view a copy of this licence, visit http://creativecommons.org/licenses/by/4.0/.

(C) The Author(s) 2022 